\title{
An Improved Lightning Search Algorithm Employed Performance Enhancement in Distribution System
}

\author{
G. Isha ${ }^{1}$ D $\cdot$ P. Jagatheeswari ${ }^{2}$
}

Received: 23 March 2021 / Accepted: 4 November 2021

(c) The Author(s) 2021

\begin{abstract}
The proposed research work minimizes the power loss in distribution system under load conditions which is the major issue nowadays that has been reduced to reach the maximum possible power for satisfying the customer needs. Optimal siting of Distribution Static Compensator (DSTATCOM) and Photo-Voltaic (PV) array in distribution system is used to attain voltage profile improvement, reduced voltage instability and less power loss. For this, Improved Lightning Search Algorithm (ILSA) has been proposed to accomplish the objectives. The proposed ILSA has reached the Voltage Stability Index (VSI) value as 0.9877 and it outstandingly decreased the power loss to $55.92 \mathrm{~kW}$ which are validated with IEEE 30-bus system using MATLAB toolbox. The obtained results are compared with the existing optimization algorithms and it depicts that the proposed ILSA is more advantageous than other optimization algorithms.
\end{abstract}

Keywords DSTATCOM $\cdot$ Load conditions $\cdot$ Optimization $\cdot$ PV array $\cdot$ Radial distribution network

\section{Introduction}

At present, electrical energy demand increases because of the increasing utilization in industries and in daily life. Good quality and uninterrupted electrical energy should be provided to the customer for their needs is an important issue at present. To meet this challenge, power plants are increasing to deliver the expected energy demand. Consequently, emissions present in air causes harmful defects and using fuels to generate electricity are going to be exhausted. Because of this, renewable energy sources such as wind energy, solar system, hydro power plant etc., are used presently in the distribution systems. To obtain the maximum potential benefits of distributed generation, optimal allocation is important in distribution systems [1, 2]. Conservation Voltage Reduction

G. Isha

gishq86@gmail.com

P. Jagatheeswari

jagatheeswarissk@gmail.com

1 Department of Electrical and Electronics Engineering, Ponjesly College of Engineering, Affiliated To Anna University, Nagercoil, Tamilnadu, India

2 Department of Electronics and Communication Engineering, Ponjesly College of Engineering, Affiliated To Anna University, Nagercoil, Tamilnadu, India
(CVR) in real time management has been solved with optimally placing DG in the distribution systems [3-6].

To enhance the voltage profile values under load conditions DG has been located optimally in the distribution system [7]. However, improving voltage stability value is needed in distribution system. To achieve this aspect, renewable energy-based DG has been optimally allocated in the distributed systems $[8,9]$. To attain the maximum power loss reduction in distribution system, multiple DGs are placed appropriately with new method [10]. However, PV array-based DG in distribution system for optimal location requires reactive power compensation [11].

Because of reactive power compensation in distribution system, power electronics component like Distributed Flexible Alternating Current Transmission System (DFACTS) devices came into picture because of its low cost, portable size and increasing system stability [12]. Many DFACTS devices are there like DSTATCOM, Unified Power Flow Controller (UPFC), Static Var Compensator (SVC) etc. In distributed system, SVC device has been used as reactive power controller to improve the voltage profile values and to reduce the system losses [13].

Many optimization techniques have been proposed with FACTS devices to improve the system stability. The Particle Swarm Optimization (PSO) technique is used with FACTS devices for improving the system loading capability with 
optimal allocation [14, 15]. In DFACTS devices, DSTATCOM is the most advantageous and portable size controller to reduce the power loss and voltage instability $[16,17]$. The Bacteria Foraging (BF) algorithm has been proposed to optimize the Real Power Loss (RPL) and voltage stability limit. The BF algorithm depends on random search directions which may lead to delay in reaching the global solution [18].

For finding the optimal allocation of DG and DSTATCOM, several optimization techniques have been proposed. This consists of Harmony Search Algorithm (HSA) [19], Improved Harmony Search Algorithm (IHSA) [20], Artificial Bee Colony Optimization (ABCO) and Interactive Artificial Bee Colony Optimization (IABCO) [21], complex artificial bee colony algorithm [22], Comprehensive Learning Particle Swarm Optimization (CLPSO) [23], hybrid algorithm [24] and Grey Wolf Optimization (GWO) [25], Differential Evolution Algorithm (DEA) [26] etc. However, these algorithms cause slow convergence speed, low solving precision, bad local searching capability and lack in providing the best fit with respect to limited time duration.

To solve the constrained optimization problems, hybrid algorithms like Genetic Algorithm-Gravitational Search Algorithm (GA-GSA) [27], Particle Swarm Optimization-Genetic Algorithm (PSO-GA) [28], Time Varying Acceleration Coefficient-Particle Swarm Optimization (TVAC-PSO) [29], Gravitational Search Algorithm-Genetic Algorithm (GSA-GA) [30] have been used.

To attain the global minima, an efficient optimization technique is required. For this exploitation and exploration, ILSA is proposed for optimal placement. The power flow can be controlled by Newton-Raphson method in the radial distribution system, by which the voltage profile and losses of the system for various load levels i.e., 0.5 (light), 1.0 (nominal), and 1.6 (heavy) can be found.

The load models and impact indices are presented in Sect. 2. Illustrations of proposed methodology is given in Sect. 3. Analysis of the results is resumed in Sect. 4 and conclusions are presented in Sect. 5.

\section{Load Models and Impact Indices}

The power equations can be written as,

$$
\begin{aligned}
& p_{j}=\sum_{k=1}^{n}\left|Y_{j k}\right|\left|e_{k}\right|\left|e_{j}\right| \cos \left(\theta_{j k}+\phi_{k}-\phi_{j}\right) \\
& q_{j}=-\sum_{k=1}^{n}\left|Y_{j k}\right|\left|e_{k}\right|\left|e_{j}\right| \sin \left(\theta_{j k}+\phi_{k}-\phi_{j}\right)
\end{aligned}
$$

\subsection{Power Balance Limits}

$$
\sum_{j=1}^{N} p_{p v, j}=\sum_{j=1}^{N} p_{D S T A T, k}+p_{\text {loss }}
$$

\subsection{Voltage Limits}

0.95 perunit $\leq\left|e_{j}\right| \leq 1.10$ perunit

\subsection{Voltage Stability Index (VSI)}

VSI among sending and receiving end can be expressed as,

$V S I=\frac{4 z_{j k}^{2} q_{j}}{e_{j}^{2} x_{j k}}$

where, ' $z_{j k}$ ' is the magnitude of line impedance, ' $x_{j k}$ ' is the line reactance, ' $q_{j}$ ' is the reactive power value of receiving end and ' $e_{j}$ ' is the voltage of sending end. The highest VSI value of bus can be chosen as optimum bus for placement of DSTATCOM and PV array.

\subsection{Total Voltage Deviation (TVD)}

TVD can be written as,

$T V D=\sum_{n=1}^{k}\left|e_{n r e f}-e_{n}\right|$

where, ' $e_{n}$ ' is the bus voltage magnitude and ' $e_{\text {nref }}$ ' is the reference voltage.

\section{Proposed Methodology}

LSA is based on the natural phenomenon of lightning and it is inspired by the probabilistic nature and sinuous characteristics of lightning discharges during a thunderstorm. The mechanism of step leader propagation utilizing the theory of fast particles known as projectiles. In LSA, three types of projectile models named transition, space and lead projectiles are used to find the optimal solution. Like other algorithms, here projectiles are act as particles. The advantage of using LSA compared to other optimization algorithm is fast tracking and high accurate results. However, its searching capability is very poor. To avoid this, ILSA is proposed here. The flow diagram of the proposed model has been presented in Fig. 1 to explain the working of ILSA easily. 
Fig. 1 Flow diagram of proposed mode

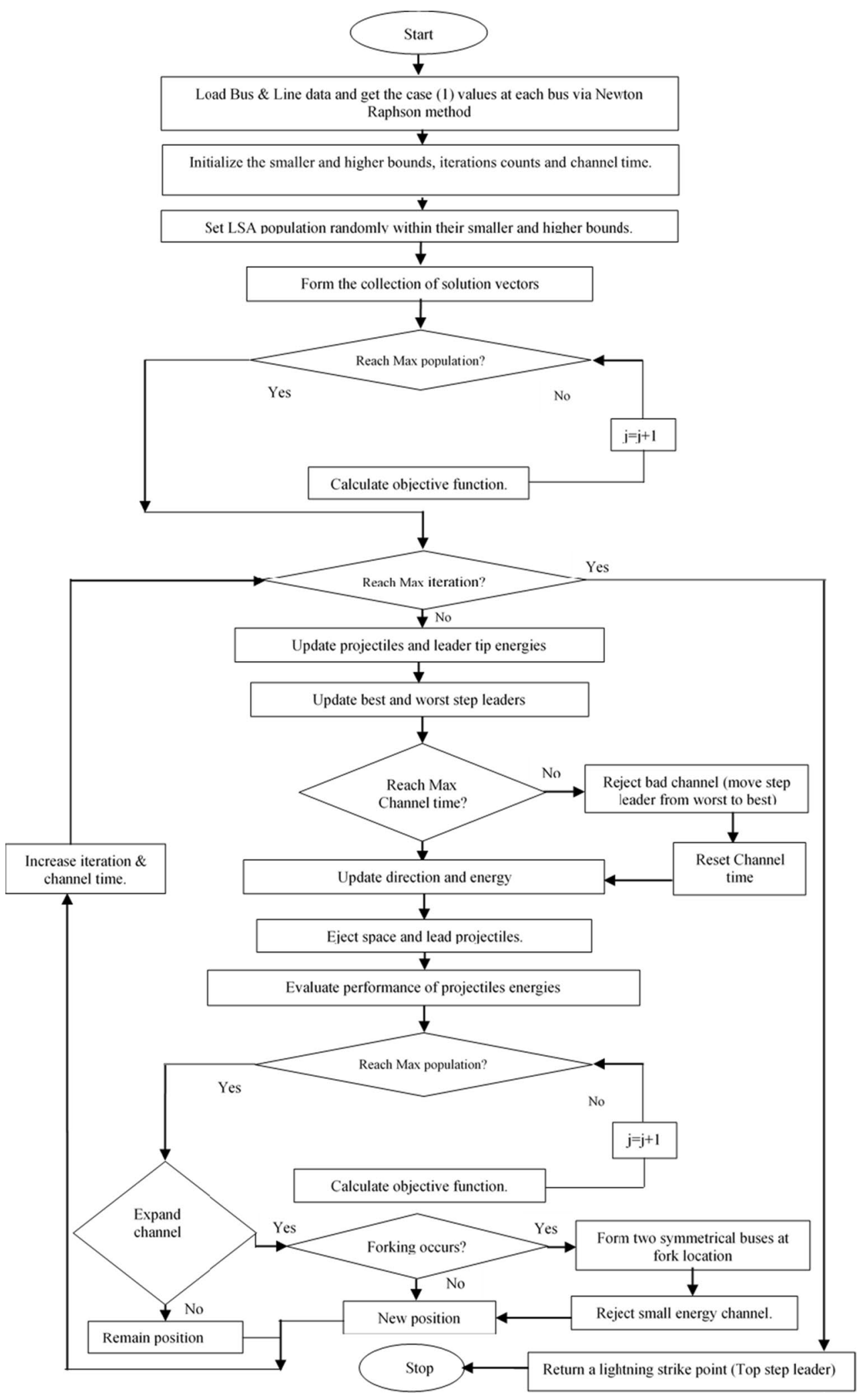


The proposed method to improve LSA with the allocation of DSTATCOM and PV array simultaneously in the distribution network for various load conditions to accomplish the goals is abridged in the following steps.

Step 1: Load the bus data and line data to get the base case (1) values at each bus using Newton-Raphson's method of load flow analysis, under various load conditions like light load (0.5), nominal load (1), and heavy load (1.6).

Step 2: Initialize the higher and smaller limits, iteration counts, channel time for the limits.

Step 3: Calculate the value of KVAR to be added within the smaller and higher limits and set the random LSA population.

Step 4: Form the collection of solution vectors $\mathrm{f}(x)$.

Step 5: Check whether the maximum population has been reached by the obtained value. If this has been satisfied, then proceed with the next step or else store the value and increase the value of ' $j$ '.

Step 6: Check whether the maximum iteration has been reached by the obtained value. If this has been satisfied, then save the value as the final optimal value otherwise continue the next step.

Step 7: The projectile values and leader tips energies are updated.

Step 8: The worst and best optimal solutions are updated and estimate the objective function of the step leader $f(\mathrm{SL})$. Rank the step leader in descending order.

Step 9: Check whether the maximum channel time has been reached by the obtained value. If this has been satisfied, update the direction and energy otherwise eliminate the worst channel and then update the values.

Step 10: Assess the performance of the projectile's energies.

Step 11: Repeat the same procedure in step 5. Update the LSA projectile value using fuzzy. Make another solution by revising LSA and make a comparison with the fitness value of the new solution and the best solution. If the newly formed solution has a better fitness value than best solution, then save this as the best solution.

Step 12: Evaluate the actual function of solution vector $f(x)$.

Step 13: If $f(x)>f(\mathrm{SL})$ condition is satisfied then check the forking event possibility and update the SL positions else stay on the same point and increase the iteration value and the channel time.

Step 14: Next go to step 6, check whether the maximum iteration is reached. If this has been satisfied then save the value as the best result otherwise repeat the steps 7-13.

Step 15: Exhibit the optimum value.

\section{Results and Discussion}

The Optimal siting of DSTATCOM and PV array using ILSA for different load conditions has been done in IEEE 30-bus test system using MATLAB software to calculate the power loss and voltage profile values. In this, the load factor values of light load, nominal load and heavy load are $0.5,1.0$ and 1.6 respectively. The four cases used to demonstrate the usefulness of the proposed ILSA are,

Case (1): system without compensation under load conditions.

Case (2): system with DSTATCOM under load conditions.

Case (3): system with PV array under load conditions.

Case (4): system with DSTATCOM and PV array under load conditions.

Case (1): system without compensation under load conditions

Load flow analysis is done using the Newton Raphson method for an uncompensated IEEE 30-bus system. At light load, the minimum voltage is $0.9850 \mathrm{pu}$ and the minimum angle is -17.7024 which are presented in Table 1 . At this condition, the power loss is $369.11 \mathrm{~kW}$ and VSI value is 0.8436 which are given in Table 5 . The optimal location can be found by using the Improved Lightning Search Algorithm. At nominal load, the minimum voltage is $0.9761 \mathrm{pu}$ and the minimum angle is -20.6883 which are shown in Table 1. In this condition, the power loss is $495.59 \mathrm{~kW}$ which is given in Table 5. At heavy load, the minimum voltage is $0.9668 \mathrm{pu}$ and the minimum angle is -21.4409 and these values are tabulated in Table 1. At heavy load, the power loss is $879.46 \mathrm{~kW}$ which is shown in Table 5. Figure 2 shows the voltage graph under various load levels for network without compensation.

Case (2): System with DSTATCOM under load conditions

The voltage profile values have been calculated and are presented in Table 2. At light load, the power loss is $40.98 \mathrm{~kW}$ and VSI value is 0.9811 which are observed from Table 5. At nominal load, the power is $83.34 \mathrm{~kW}$ and the VSI value is 0.9795 which are tabulated in Table 5. At heavy load, the power loss is $143.28 \mathrm{~kW}$ and the VSI value is 0.9795 which are presented in Table 5. Figure 3 shows the voltage graph under various load levels for network with DSTATCOM under load conditions.

Case (3): system with PV array under load conditions

The voltage values have been calculated and are given in Table 3. At light load, the power loss is $45.64 \mathrm{~kW}$ and the VSI value is 0.9804 which are shown in Table 5. At nominal load, the power loss is $69.43 \mathrm{~kW}$ and the VSI value is 0.9802 which are shown in Table 5. At heavy load, the power loss is $224.27 \mathrm{~kW}$ and VSI value is 0.9800 
Table 1 Voltage profile and angle in each bus without compensation of load variation

\begin{tabular}{|c|c|c|c|c|c|c|}
\hline \multirow{2}{*}{$\begin{array}{l}\text { Bus } \\
\text { No }\end{array}$} & \multicolumn{2}{|l|}{ Light load } & \multicolumn{2}{|l|}{ Nominal load } & \multicolumn{2}{|l|}{ Heavy load } \\
\hline & Voltage (pu) & Angle (degree) & Voltage (pu) & Angle (degree) & Voltage (pu) & Angle (degree) \\
\hline 1 & 1.0640 & 0.0000 & 1.0640 & 0.0000 & 1.0612 & 0.0000 \\
\hline 2 & 1.0490 & -5.3412 & 1.0390 & -6.0260 & 1.0362 & -6.4819 \\
\hline 3 & 1.0231 & -7.4499 & 1.0198 & -8.4944 & 1.0147 & -9.1816 \\
\hline 4 & 1.0137 & -9.1841 & 1.0102 & -10.4676 & 1.0051 & -11.3139 \\
\hline 5 & 1.0140 & -14.0498 & 1.0140 & -15.2382 & 1.0112 & -16.0565 \\
\hline 6 & 1.0130 & -10.9504 & 1.0104 & -12.4381 & 1.0059 & -13.4217 \\
\hline 7 & 1.0057 & -12.7467 & 1.0039 & -14.1403 & 0.9999 & -15.0765 \\
\hline 8 & 1.0140 & -11.7166 & 1.0140 & -13.2988 & 1.0112 & -14.3481 \\
\hline 9 & 1.0382 & -13.9513 & 1.0356 & -16.1511 & 1.0309 & -17.5931 \\
\hline 10 & 1.0207 & -15.5612 & 1.0172 & -18.0248 & 1.0118 & -19.6406 \\
\hline 11 & 1.0760 & -13.9513 & 1.0760 & -16.2581 & 1.0732 & -17.7655 \\
\hline 12 & 1.0471 & -14.9893 & 1.0449 & -17.2819 & 1.0404 & -18.7888 \\
\hline 13 & 1.0640 & -14.9893 & 1.0640 & -17.3541 & 1.0612 & -18.9050 \\
\hline 14 & 1.0298 & -15.8711 & 1.0262 & -18.3374 & 1.0207 & -19.9568 \\
\hline 15 & 1.0232 & -15.8859 & 1.0191 & -18.3805 & 1.0134 & -20.0174 \\
\hline 16 & 1.0286 & -15.5029 & 1.0252 & -17.9493 & 1.0198 & -19.5540 \\
\hline 17 & 1.0177 & -15.7563 & 1.0139 & -18.2488 & 1.0084 & -19.8836 \\
\hline 18 & 1.0099 & -16.4909 & 1.0045 & -19.1562 & 0.9978 & -20.9030 \\
\hline 19 & 1.0053 & -16.6534 & 0.9997 & -19.3463 & 0.9929 & -21.1114 \\
\hline 20 & 1.0083 & -16.4388 & 1.0030 & -19.1041 & 0.9965 & -20.8506 \\
\hline 21 & 1.0073 & -16.1068 & 1.0028 & -18.6650 & 0.9968 & -20.3430 \\
\hline 22 & 1.0114 & -15.8714 & 1.0065 & -18.4887 & 1.0002 & -20.2019 \\
\hline 23 & 1.0076 & -16.1176 & 1.0030 & -18.6913 & 0.9969 & -20.3789 \\
\hline 24 & 0.9988 & -16.1924 & 0.9930 & -18.8952 & 0.9860 & -20.6639 \\
\hline 25 & 1.0044 & -15.9724 & 0.9972 & -18.7905 & 0.9894 & -20.6305 \\
\hline 26 & 0.9865 & -16.4031 & 0.9765 & -19.4525 & 0.9668 & -21.4409 \\
\hline 27 & 1.0166 & -15.5608 & 1.0110 & -18.2099 & 1.0041 & -19.9420 \\
\hline 28 & 1.0112 & -11.6080 & 1.0080 & -13.2540 & 1.0030 & -14.3383 \\
\hline 29 & 0.9966 & -16.8073 & 0.9881 & -19.7428 & 0.9794 & -21.6629 \\
\hline 30 & 0.9850 & -17.7024 & 0.9761 & -20.6883 & 0.9671 & -22.6469 \\
\hline
\end{tabular}

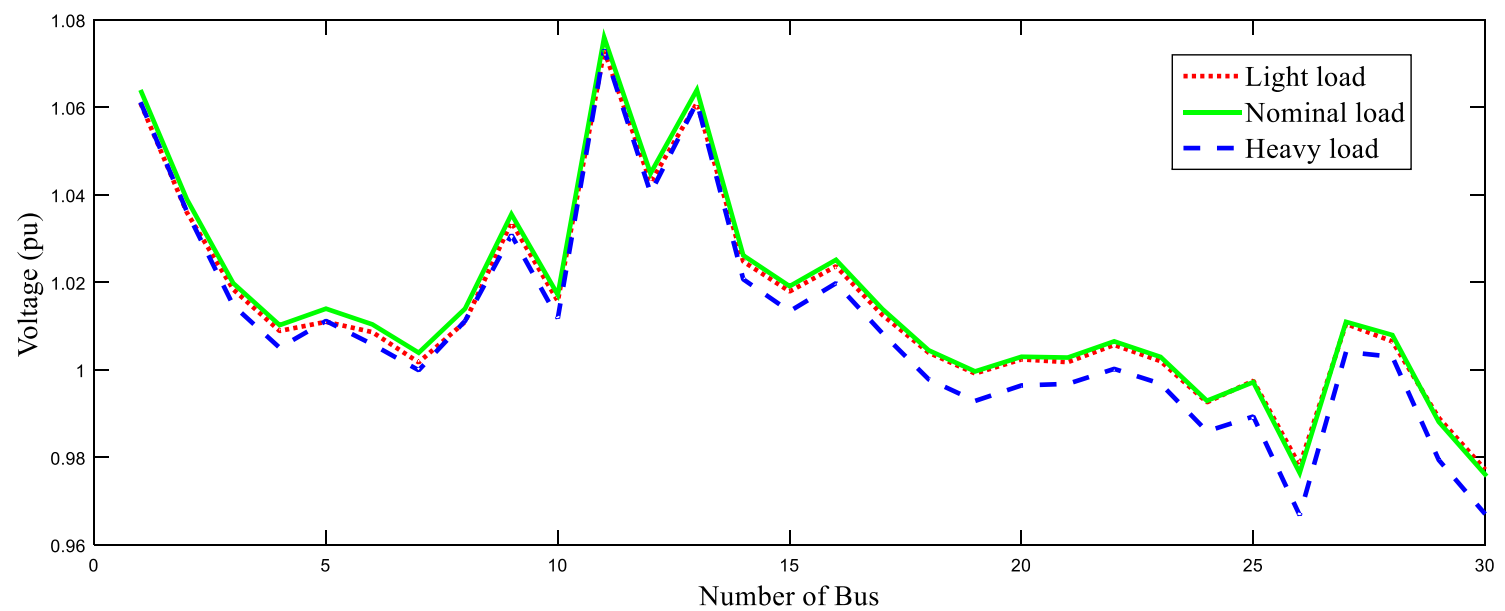

Fig. 2 Network without compensation under load conditions 
Table 2 Voltage profile and angle in each bus with DSTATCOM of load variation

\begin{tabular}{|c|c|c|c|c|c|c|}
\hline \multirow{2}{*}{$\begin{array}{l}\text { Bus } \\
\text { No }\end{array}$} & \multicolumn{2}{|l|}{ Light load } & \multicolumn{2}{|l|}{ Nominal load } & \multicolumn{2}{|l|}{ Heavy load } \\
\hline & Voltage (pu) & Angle (degree) & Voltage (pu) & Angle (degree) & Voltage (pu) & Angle (degree) \\
\hline 1 & 1.0610 & 0.0000 & 1.0680 & 0.0000 & 1.0619 & 0.0000 \\
\hline 2 & 1.0440 & -5.1683 & 1.0510 & -5.4304 & 1.0449 & -5.9216 \\
\hline 3 & 1.0239 & -7.4523 & 1.0295 & -7.8631 & 1.0185 & -8.5600 \\
\hline 4 & 1.0154 & -9.1719 & 1.0210 & -9.6744 & 1.0092 & -10.5352 \\
\hline 5 & 1.0110 & -13.4249 & 1.0180 & -13.8151 & 1.0119 & -14.7441 \\
\hline 6 & 1.0166 & -10.8382 & 1.0225 & -11.4154 & 1.0093 & -12.3949 \\
\hline 7 & 1.0099 & -11.8996 & 1.0162 & -12.4138 & 1.0057 & -13.3868 \\
\hline 8 & 1.0210 & -11.6767 & 1.0280 & -12.2851 & 1.0119 & -13.2703 \\
\hline 9 & 1.0443 & -14.1770 & 1.0506 & -15.0521 & 1.0400 & -16.5370 \\
\hline 10 & 1.0278 & -15.9032 & 1.0340 & -16.8799 & 1.0230 & -18.5558 \\
\hline 11 & 1.0830 & -14.2297 & 1.0900 & -15.1562 & 1.0839 & -16.7062 \\
\hline 12 & 1.0562 & -15.3610 & 1.0630 & -16.2686 & 1.0547 & -17.8734 \\
\hline 13 & 1.0720 & -15.3964 & 1.0790 & -16.3385 & 1.0729 & -17.9868 \\
\hline 14 & 1.0460 & -16.5778 & 1.0530 & -17.5818 & 1.0469 & -19.4267 \\
\hline 15 & 1.0331 & -16.3360 & 1.0393 & -17.3282 & 1.0301 & -19.0683 \\
\hline 16 & 1.0366 & -15.8965 & 1.0428 & -16.8681 & 1.0330 & -18.5554 \\
\hline 17 & 1.0250 & -16.1265 & 1.0311 & -17.1146 & 1.0203 & -18.8179 \\
\hline 18 & 1.0182 & -16.9765 & 1.0238 & -18.0386 & 1.0128 & -19.8775 \\
\hline 19 & 1.0129 & -17.1282 & 1.0183 & -18.1998 & 1.0068 & -20.0499 \\
\hline 20 & 1.0157 & -16.8935 & 1.0212 & -17.9546 & 1.0097 & -19.7801 \\
\hline 21 & 1.0147 & -16.5051 & 1.0206 & -17.5199 & 1.0092 & -19.2710 \\
\hline 22 & 1.0179 & -16.2857 & 1.0235 & -17.3316 & 1.0114 & -19.1093 \\
\hline 23 & 1.0151 & -16.5300 & 1.0209 & -17.5524 & 1.0096 & -19.3158 \\
\hline 24 & 1.0050 & -16.6461 & 1.0102 & -17.7285 & 0.9970 & -19.5651 \\
\hline 25 & 1.0089 & -16.4626 & 1.0133 & -17.6038 & 0.9977 & -19.4957 \\
\hline 26 & 0.9897 & -16.9991 & 0.9929 & -18.2444 & 0.9754 & -20.2923 \\
\hline 27 & 1.0211 & -15.9616 & 1.0262 & -17.0280 & 1.0107 & -18.7984 \\
\hline 28 & 1.0152 & -11.5765 & 1.0209 & -12.2209 & 1.0063 & -13.2970 \\
\hline 29 & 0.9998 & -17.3300 & 1.0037 & -18.5147 & 0.9862 & -20.4965 \\
\hline 30 & 0.9882 & -18.2362 & 0.9919 & -19.4308 & 0.9739 & -21.4669 \\
\hline
\end{tabular}

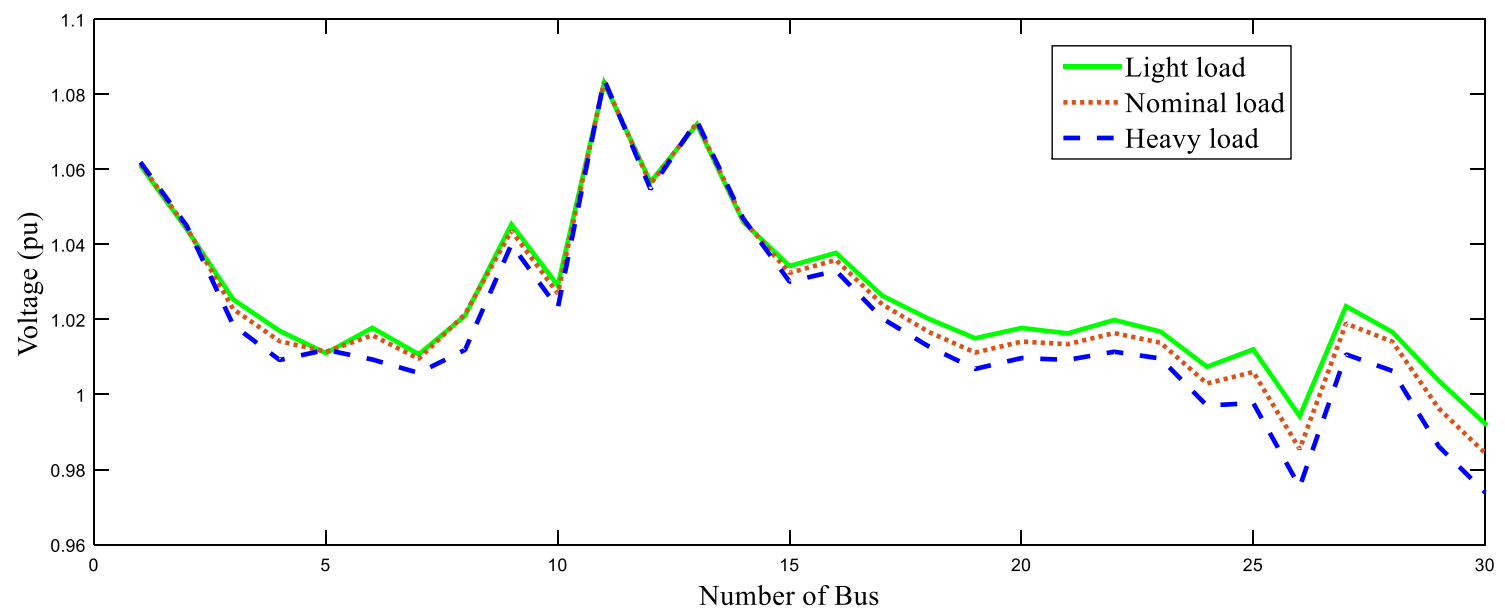

Fig. 3 Networks with DSTATCOM under load conditions 
Table 3 Voltage profile and angle in each bus with PV array of load variation

\begin{tabular}{|c|c|c|c|c|c|c|}
\hline \multirow{2}{*}{$\begin{array}{l}\text { Bus } \\
\text { No }\end{array}$} & \multicolumn{2}{|l|}{ Light load } & \multicolumn{2}{|l|}{ Nominal load } & \multicolumn{2}{|l|}{ Heavy load } \\
\hline & Voltage (pu) & Angle (degree) & Voltage (pu) & Angle (degree) & Voltage (pu) & Angle (degree) \\
\hline 1 & 1.0700 & 0.0000 & 1.0725 & 0.0000 & 1.0750 & 0.0000 \\
\hline 2 & 1.0550 & -5.6079 & 1.0475 & -5.7811 & 1.0500 & -6.1617 \\
\hline 3 & 1.0287 & -7.8868 & 1.0274 & -8.3875 & 1.0278 & -8.9672 \\
\hline 4 & 1.0195 & -9.7181 & 1.0176 & -10.3362 & 1.0178 & -11.0491 \\
\hline 5 & 1.0200 & -14.4483 & 1.0225 & -15.0588 & 1.0250 & -15.6962 \\
\hline 6 & 1.0189 & -11.5513 & 1.0184 & -12.2896 & 1.0190 & -13.1139 \\
\hline 7 & 1.0116 & -13.2722 & 1.0122 & -13.9703 & 1.0135 & -14.7322 \\
\hline 8 & 1.0200 & -12.3339 & 1.0225 & -13.1452 & 1.0250 & -14.0274 \\
\hline 9 & 1.0485 & -14.8456 & 1.0492 & -15.9186 & 1.0467 & -17.1399 \\
\hline 10 & 1.0305 & -16.5478 & 1.0310 & -17.7395 & 1.0299 & -19.1054 \\
\hline 11 & 1.0920 & -14.8976 & 1.0945 & -16.0224 & 1.0870 & -17.3075 \\
\hline 12 & 1.0588 & -15.9282 & 1.0596 & -17.0299 & 1.0603 & -18.3193 \\
\hline 13 & 1.0800 & -15.9633 & 1.0825 & -17.0998 & 1.0850 & -18.4309 \\
\hline 14 & 1.0407 & -16.8724 & 1.0409 & -18.0565 & 1.0407 & -19.4427 \\
\hline 15 & 1.0337 & -16.8928 & 1.0337 & -18.0942 & 1.0332 & -19.4929 \\
\hline 16 & 1.0393 & -16.4943 & 1.0396 & -17.6727 & 1.0391 & -19.0405 \\
\hline 17 & 1.0277 & -16.7557 & 1.0280 & -17.9591 & 1.0270 & -19.3448 \\
\hline 18 & 1.0195 & -17.5619 & 1.0190 & -18.8452 & 1.0173 & -20.3368 \\
\hline 19 & 1.0147 & -17.7312 & 1.0141 & -19.0280 & 1.0121 & -20.5323 \\
\hline 20 & 1.0177 & -17.5069 & 1.0173 & -18.7917 & 1.0154 & -20.2786 \\
\hline 21 & 1.0168 & -17.1287 & 1.0171 & -18.3668 & 1.0159 & -19.7949 \\
\hline 22 & 1.0203 & -16.9247 & 1.0207 & -18.1989 & 1.0197 & -19.6669 \\
\hline 23 & 1.0171 & -17.1473 & 1.0173 & -18.3939 & 1.0162 & -19.8338 \\
\hline 24 & 1.0070 & -17.2758 & 1.0076 & -18.6065 & 1.0072 & -20.1472 \\
\hline 25 & 1.0100 & -17.2758 & 1.0125 & -18.6065 & 1.0150 & -20.2314 \\
\hline 26 & 0.9909 & -17.0968 & 0.9921 & -18.5454 & 0.9930 & -21.0004 \\
\hline 27 & 1.0223 & -17.6321 & 1.0241 & -19.1870 & 1.0262 & -21.0004 \\
\hline 28 & 1.0167 & -16.6183 & 1.0167 & -17.9333 & 1.0173 & -19.4589 \\
\hline 29 & 1.0011 & -12.2720 & 1.0016 & -13.1009 & 1.0021 & -14.0271 \\
\hline 30 & 0.9894 & -17.9834 & 0.9897 & -19.4262 & 0.9901 & -21.1047 \\
\hline
\end{tabular}

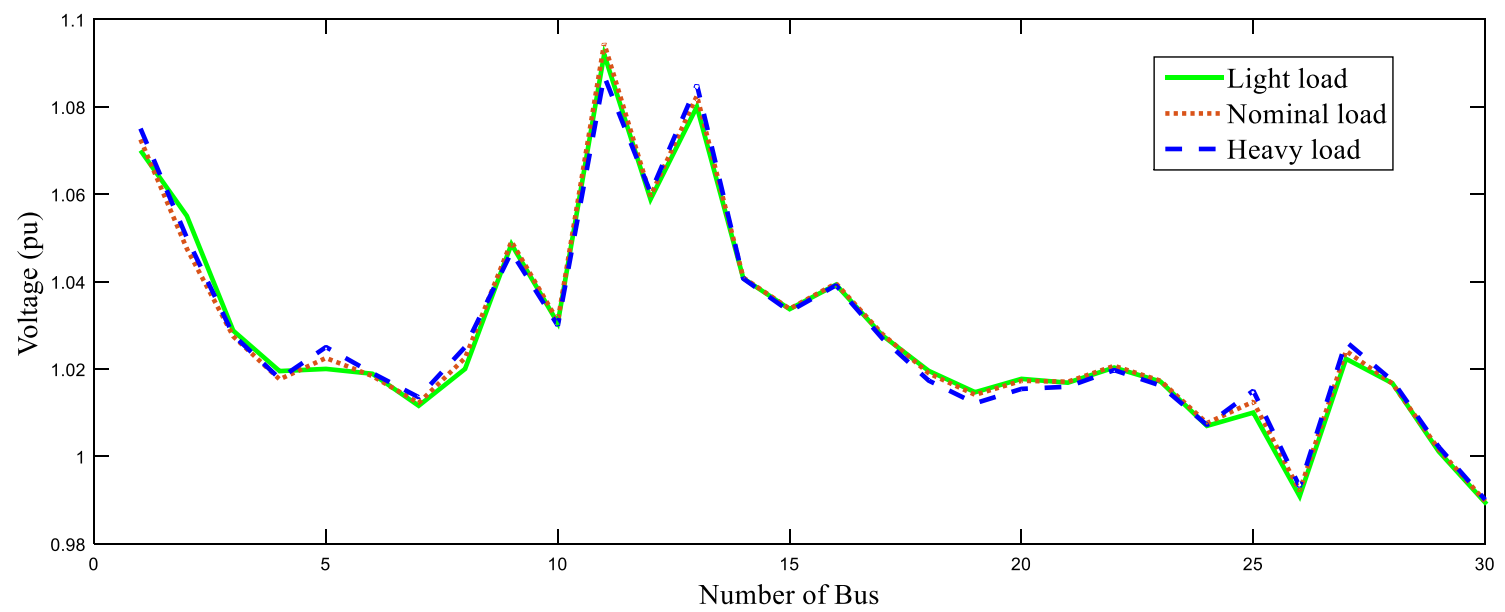

Fig. 4 Network with PV array under load conditions 
Table 4 Voltage profile and angle in each bus with DSTATCOM and PV array of load variation

\begin{tabular}{|c|c|c|c|c|c|c|}
\hline \multirow{2}{*}{$\begin{array}{l}\text { Bus } \\
\text { No }\end{array}$} & \multicolumn{2}{|l|}{ Light load } & \multicolumn{2}{|l|}{ Nominal load } & \multicolumn{2}{|l|}{ Heavy load } \\
\hline & Voltage (pu) & Angle (degree) & Voltage (pu) & Angle (degree) & Voltage (pu) & Angle (degree) \\
\hline 1 & 1.0700 & 0.0000 & 1.0725 & 0.0000 & 1.0750 & 0.0000 \\
\hline 2 & 1.0530 & -5.0772 & 1.0555 & -5.3851 & 1.0580 & -5.7603 \\
\hline 3 & 1.0346 & -7.3374 & 1.0357 & -7.8129 & 1.0365 & -8.3902 \\
\hline 4 & 1.0264 & -9.0277 & 1.0275 & -9.6104 & 1.0282 & -10.3182 \\
\hline 5 & 1.0200 & -13.1804 & 1.0225 & -13.6909 & 1.0250 & -14.3175 \\
\hline 6 & 1.0281 & -10.6959 & 1.0296 & -11.3689 & 1.0308 & -12.1869 \\
\hline 7 & 1.0205 & -11.7166 & 1.0223 & -12.3364 & 1.0239 & -13.0918 \\
\hline 8 & 1.0300 & -11.4869 & 1.0325 & -12.1980 & 1.0350 & -13.0634 \\
\hline 9 & 1.0563 & -13.8970 & 1.0581 & -14.8893 & 1.0596 & -16.0927 \\
\hline 10 & 1.0466 & -15.5397 & 1.0484 & -16.6442 & 1.0500 & -17.9835 \\
\hline 11 & 1.0820 & -13.9492 & 1.0845 & -14.9932 & 1.0870 & -16.2583 \\
\hline 12 & 1.0680 & -14.9283 & 1.0703 & -15.9566 & 1.0724 & -17.2048 \\
\hline 13 & 1.0810 & -14.9630 & 1.0835 & -16.0258 & 1.0860 & -17.3150 \\
\hline 14 & 1.0550 & -15.9516 & 1.0575 & -17.0855 & 1.0600 & -18.4634 \\
\hline 15 & 1.0477 & -15.9171 & 1.0495 & -17.0390 & 1.0510 & -18.4002 \\
\hline 16 & 1.0515 & -15.4889 & 1.0532 & -16.5864 & 1.0548 & -17.9175 \\
\hline 17 & 1.0427 & -15.7438 & 1.0444 & -16.8608 & 1.0458 & -18.2153 \\
\hline 18 & 1.0345 & -16.5524 & 1.0356 & -17.7485 & 1.0363 & -19.1988 \\
\hline 19 & 1.0301 & -16.7077 & 1.0311 & -17.9145 & 1.0316 & -19.3777 \\
\hline 20 & 1.0334 & -16.4853 & 1.0344 & -17.6801 & 1.0351 & -19.1286 \\
\hline 21 & 1.0361 & -16.1699 & 1.0376 & -17.3178 & 1.0390 & -18.7099 \\
\hline 22 & 1.0464 & -16.0530 & 1.0479 & -17.2314 & 1.0492 & -18.6600 \\
\hline 23 & 1.0372 & -16.2111 & 1.0388 & -17.3671 & 1.0401 & -18.7690 \\
\hline 24 & 1.0453 & -16.6564 & 1.0469 & -17.8801 & 1.0482 & -19.3640 \\
\hline 25 & 1.0920 & -17.3723 & 1.0945 & -18.6739 & 1.0970 & -20.2531 \\
\hline 26 & 1.0744 & -17.8289 & 1.0757 & -19.2213 & 1.0768 & -20.9093 \\
\hline 27 & 1.0827 & -16.0717 & 1.0850 & -17.2696 & 1.0872 & -18.7220 \\
\hline 28 & 1.0313 & -11.5538 & 1.0326 & -12.3047 & 1.0337 & -13.2169 \\
\hline 29 & 1.0628 & -17.2860 & 1.0639 & -18.5964 & 1.0646 & -20.1843 \\
\hline 30 & 1.0518 & -18.0870 & 1.0527 & -19.4107 & 1.0533 & -21.0155 \\
\hline
\end{tabular}

Table 5 Results of IEEE 30-bus system

\begin{tabular}{llcllll}
\hline Cases & & $\begin{array}{l}\text { Total power loss } \\
(\mathrm{kW})\end{array}$ & VSI & TVD & $\mathrm{V}_{\text {min }}$ & $\begin{array}{l}\text { \% Power } \\
\text { loss reduc- } \\
\text { tion }\end{array}$ \\
\hline 1 & & & & & - \\
& Light Load & 369.11 & 0.8436 & 3.8133 & 0.9850 & - \\
& Nominal Load & 495.59 & 0.8431 & 3.8177 & 0.9761 & - \\
& Heavy Load & 879.46 & 0.8466 & 3.8531 & 0.9668 & 88.89 \\
& Light Load & 40.98 & 0.9811 & 0.1952 & 0.9882 & 83.18 \\
& Nominal Load & 83.34 & 0.9790 & 0.1919 & 0.9919 & 83.70 \\
& Heavy Load & 143.28 & 0.9894 & 0.2080 & 0.9739 & 87.63 \\
& Light Load & 45.64 & 0.9804 & 0.7066 & 0.9894 & 85.99 \\
& Nominal Load & 69.43 & 0.9802 & 0.7060 & 0.9897 & 74.49 \\
& Heavy Load & 224.27 & 0.9800 & 0.7055 & 0.9901 & 92.68 \\
& Light Load & 27.01 & 0.9881 & 0.0078 & 1.0200 & 88.71 \\
& Nominal Load & 55.92 & 0.9877 & 0.0076 & 1.0223 & 89.11 \\
\hline
\end{tabular}


which are shown in Table 5. Figure 4 shows the voltage graph under various load levels for network with PV array.

Case (4): System with DSTATCOM and PV array under load conditions

The voltage values have been calculated and are presented in Table 4. At light load, the power loss is $27.01 \mathrm{~kW}$ and the VSI value is 0.9881 which are shown in Table 5. At nominal load, the power loss is $55.92 \mathrm{~kW}$ and the VSI value is 0.9877 which are shown in Table 5. At heavy load, the power loss is
$95.72 \mathrm{~kW}$ and the VSI value is 0.9875 which are tabulated in Table 5. Figure 5 shows the voltage graph under various load levels for network with DSTATCOM and PV array.

Table 5 represents the results of the IEEE-30 bus system with DSTATCOM and PV array for various load levels. From this, the system with DSTATCOM and PV array (case 4) for various load levels gives the better results compared to other three cases. Figure 6 depicts the comparison of total power loss for various load levels. It clearly exhibits that the

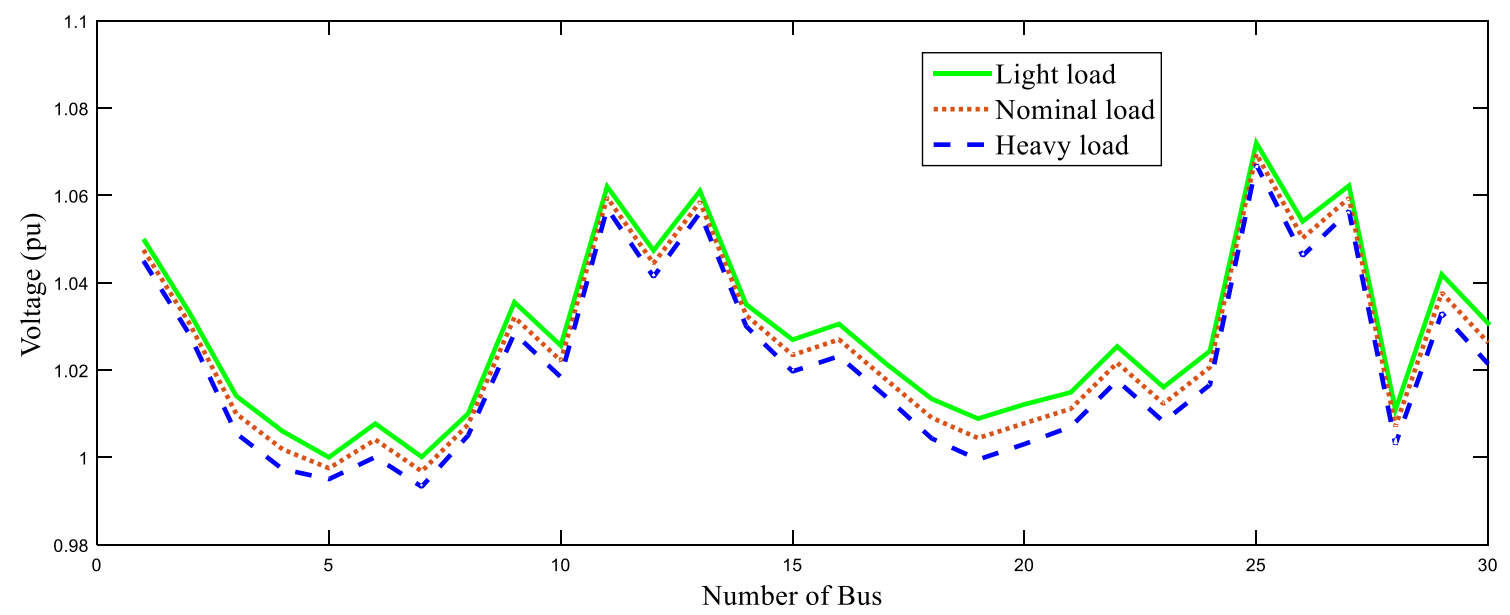

Fig. 5 Network with DSTATCOM and PV array under loading conditions

Total power loss

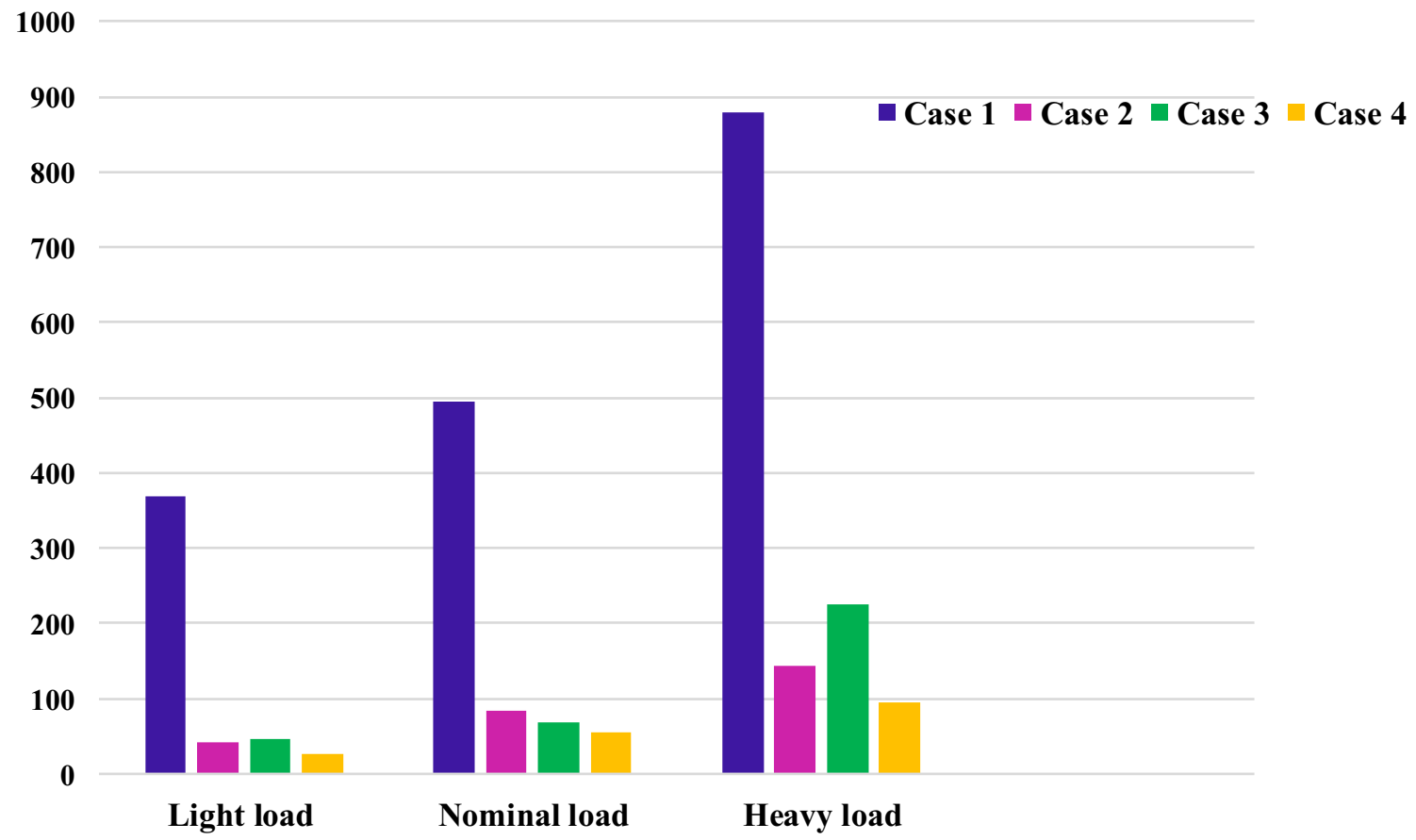

Fig. 6 Comparison of total power loss for various load conditions 


\section{\% Power loss reduction}

100
90
80
70
60
50
40
30
20
10
0

90

80

70

60

40

$\mathbf{0}$

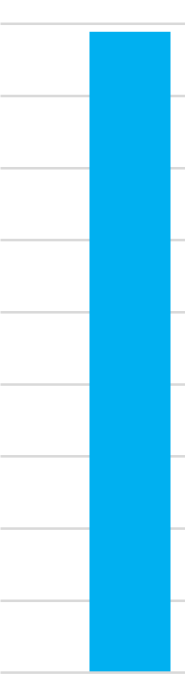

Light load

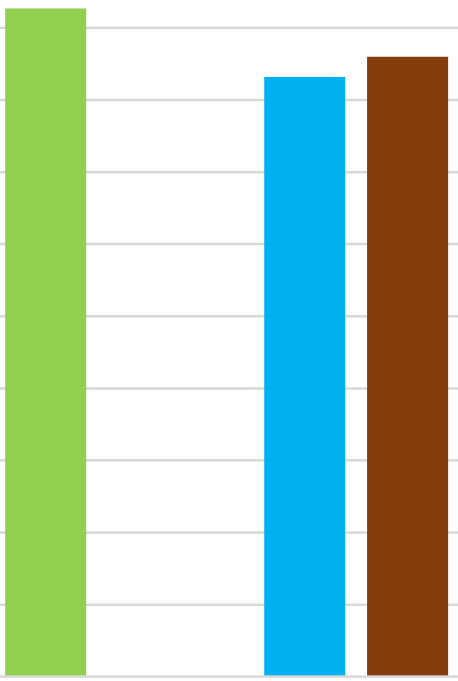

Nominal load

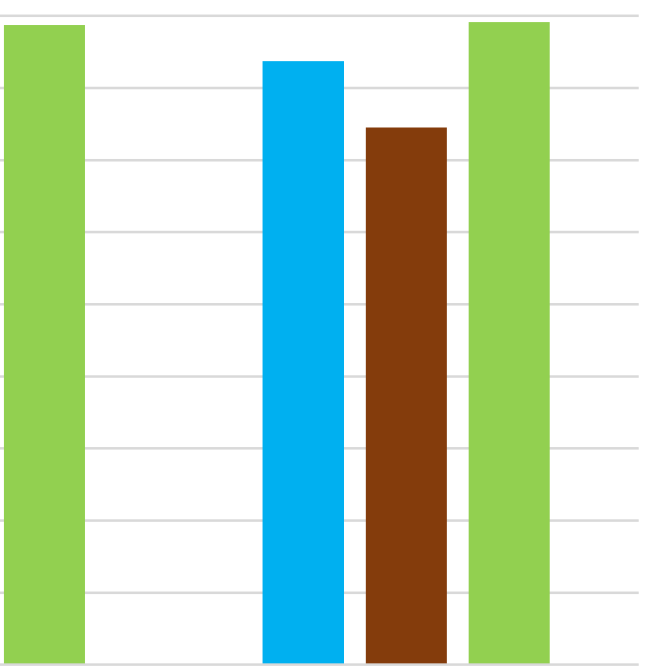

Heavy load

Case $2 \square$ Case $3 \square$ Case 4

Fig. 7 Comparison of \% power loss reduction for various load conditions

\section{VSI}

1.05

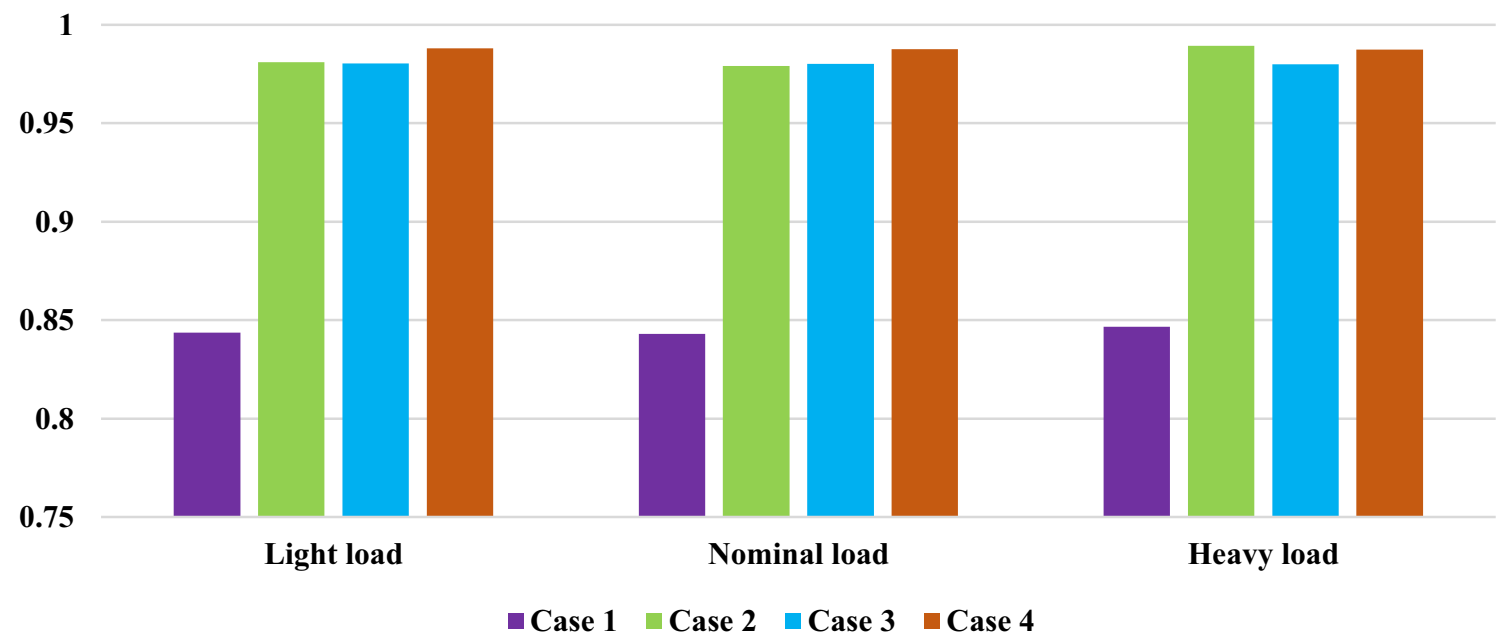

Fig. 8 Comparison of VSI for four cases under load conditions

total power loss is very low in proposed case (4). Figure 7 represents the comparison of $\%$ power loss reduction for various load levels. From this figure, the proposed case (4) has high percentage of loss reduction is verified. Figure $8 \mathrm{dem}-$ onstrates the VSI comparison for various load levels. From this, the voltage is highly stable in proposed system has been proved. Figure 9 depicts the comparison of TVD for various load levels. This figure illustrates that the proposed system has less voltage deviation. Figure 10 shows the comparison of minimum voltage $\left(\mathrm{V}_{\min }\right)$ for various load levels. 
TVD

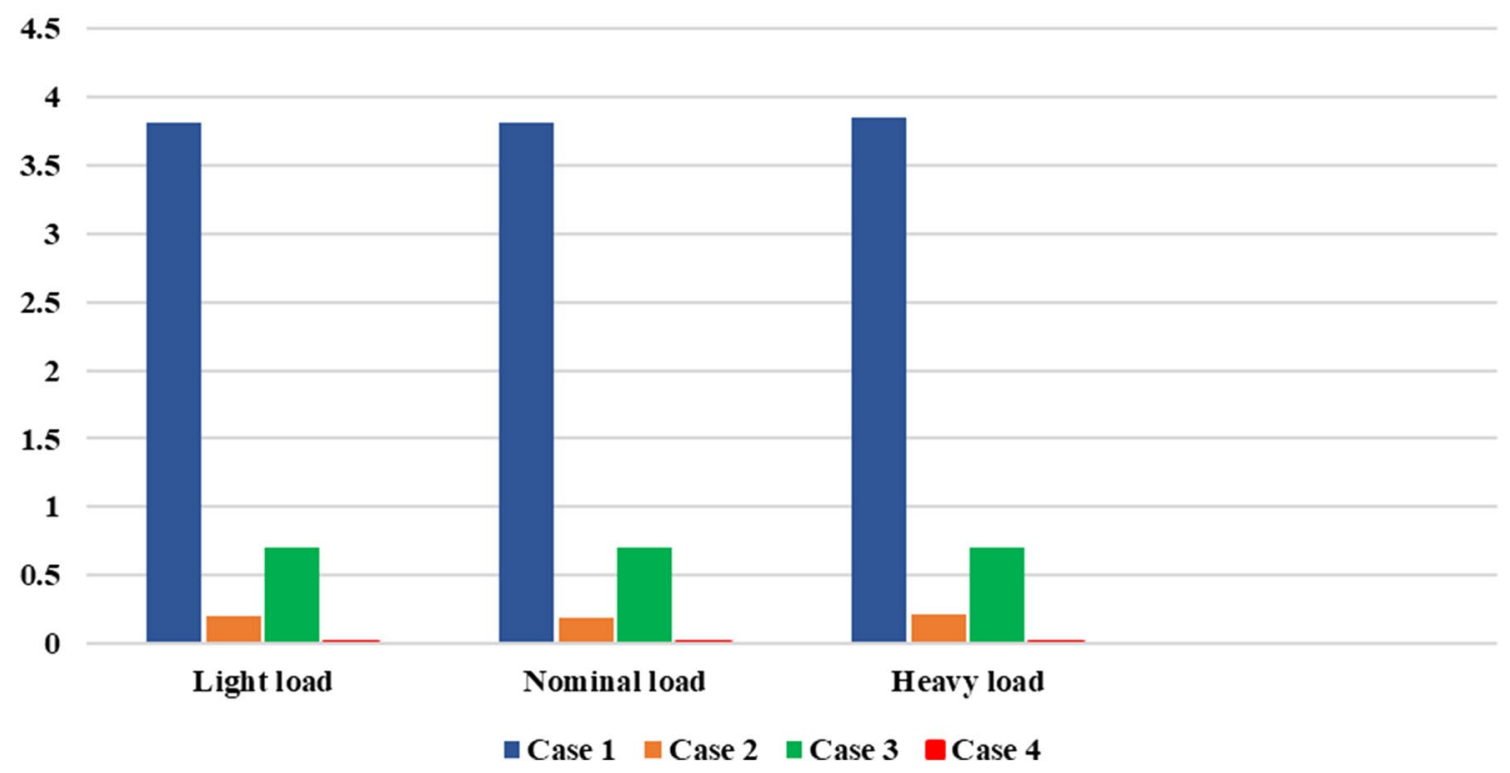

Fig. 9 Comparison of TVD for four cases under load conditions

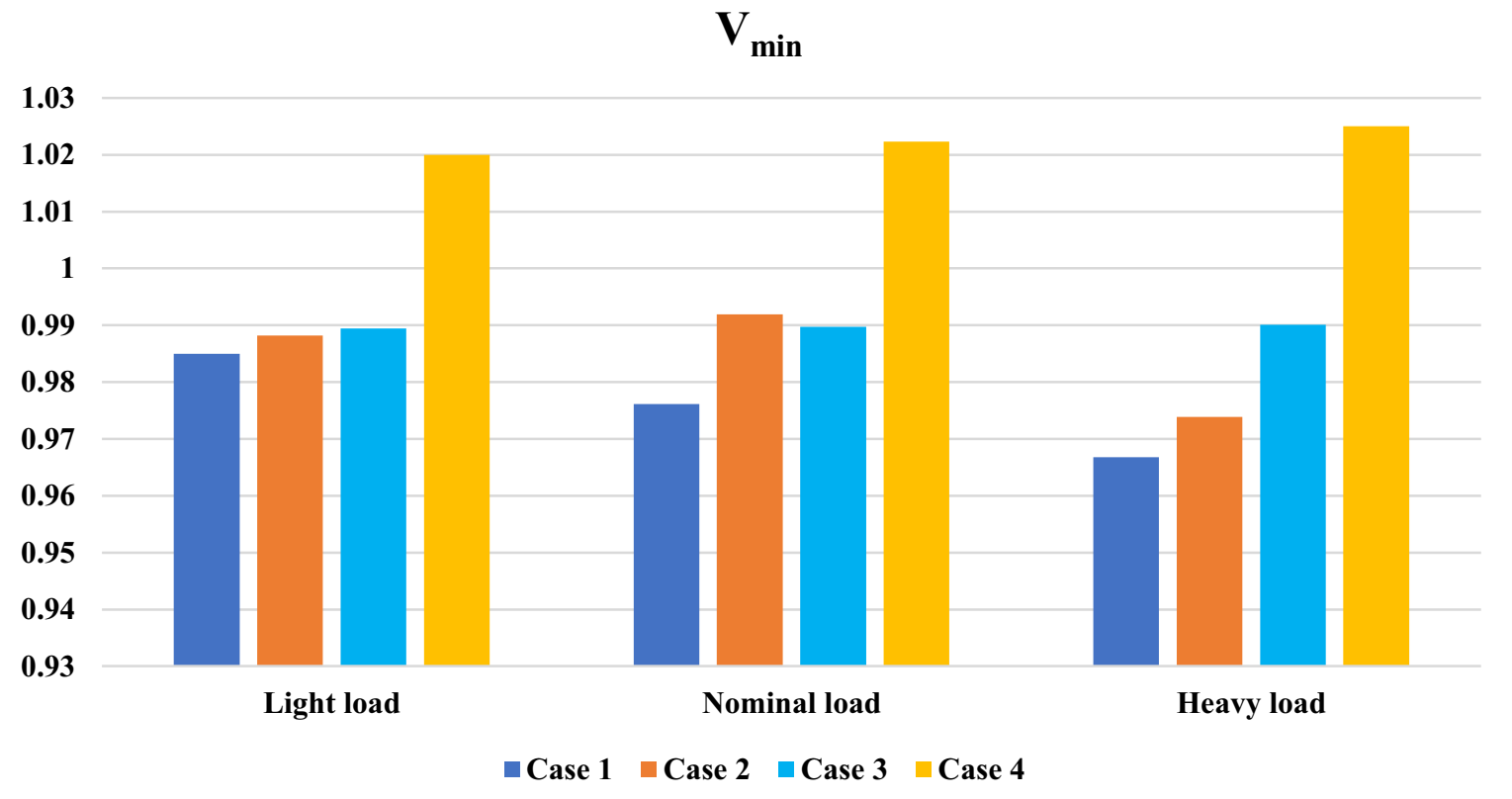

Fig. 10 Comparison of minimum voltage for four cases under load conditions

Figure 11 depicts the power loss for all the cases and the values are tabulated in Table 6. It clearly shows that the proposed system has very low loss for all the load levels.

The proposed ILSA method is compared with other algorithms which is shown in Table 7 to show the effectiveness of the proposed method with IEEE 30-bus system for various load levels. Figure 12 illustrates the comparison of power loss with existing methods. From this, the power loss in proposed method is very less has been proved. From Fig. 13, \% $\mathrm{P}_{\text {loss }}$ reduction in the proposed method is very high has been verified. Figure 14 depicts that the voltage value is improved in the proposed approach. 


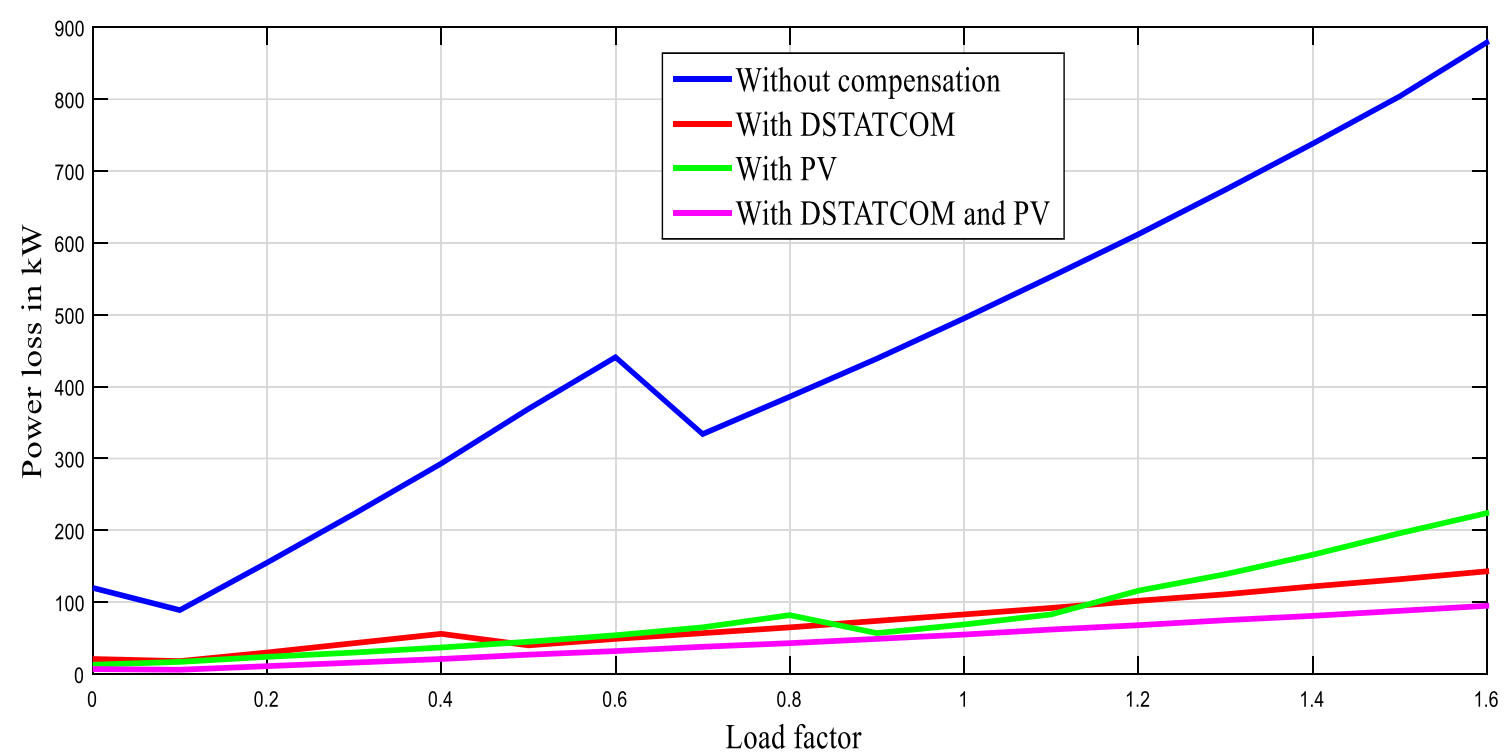

Fig. 11 Power loss Vs Load factor

Table 6 Power loss values for all cases

\begin{tabular}{|c|c|c|c|c|}
\hline \multirow[t]{2}{*}{ Load factor } & \multicolumn{4}{|c|}{ Power loss $(\mathrm{kW})$} \\
\hline & $\begin{array}{l}\text { Without } \\
\text { compensa- } \\
\text { tion }\end{array}$ & DSTATCOM & PV array & $\begin{array}{l}\text { DSTATCOM } \\
\text { and PV array }\end{array}$ \\
\hline 0 & 120 & 21.07 & 13.63 & 7.00 \\
\hline 0.1 & 89.73 & 18.34 & 17.54 & 6.82 \\
\hline 0.2 & 155.11 & 30.02 & 24.31 & 11.29 \\
\hline 0.3 & 223.45 & 43.63 & 30.74 & 16.29 \\
\hline 0.4 & 293.76 & 56.34 & 37.92 & 21.29 \\
\hline 0.5 & 369.11 & 40.98 & 45.64 & 27.01 \\
\hline 0.6 & 441.89 & 49.73 & 54.27 & 32.72 \\
\hline 0.7 & 334.34 & 57.26 & 65.92 & 38.92 \\
\hline 0.8 & 386.98 & 65.82 & 82.82 & 43.63 \\
\hline 0.9 & 439.09 & 74.82 & 57.82 & 49.06 \\
\hline 1 & 495.59 & 83.34 & 69.43 & 55.92 \\
\hline 1.1 & 553.54 & 92.62 & 83.53 & 62.73 \\
\hline 1.2 & 612.46 & 102.23 & 116.72 & 68.56 \\
\hline 1.3 & 674.01 & 111.11 & 139.72 & 75.81 \\
\hline 1.4 & 738.93 & 12,292 & 166.28 & 81.91 \\
\hline 1.5 & 804.93 & 132.92 & 196.82 & 88.23 \\
\hline 1.6 & 879.46 & 143.28 & 224.27 & 95.72 \\
\hline
\end{tabular}

\section{Conclusion}

The proposed ILSA is an effective method to optimally allocate the DSTATCOM and PV array in the distribution system for various loading conditions. Using IEEE 30-bus system, the effectiveness of the proposed ILSA method has been verified in the distribution system. The ILSA method has been investigated with the various scenarios in IEEE 30-bus system to show the proposed fourth case is more advantageous than others in reduce the power loss and voltage profile improvement. In this, the total power loss is $55.92 \mathrm{~kW}$ and the percentage power loss reduction is $88.71 \%$ by the improvement in voltage profile. Obviously, the results show the proposed method is better than other algorithms with comparison. 
Table 7 Comparative analysis of proposed algorithm with existing algorithms

\begin{tabular}{llll}
\hline Algorithms & Power loss (kW) & $\begin{array}{l}\text { Percentage power } \\
\text { loss reduction }\end{array}$ & $\begin{array}{l}\mathrm{V}_{\min } \\
(\mathrm{pu})\end{array}$ \\
\hline Genetic Algorithm (GA) [31] & 98.36 & 80.15 & 0.9506 \\
Harmony Search Algorithm (HSA) [31] & 97.13 & 80.40 & 0.9479 \\
Fire Works Algorithm (FWA) [32] & 83.91 & 83.06 & 0.9612 \\
Comprehensive Teaching Learning Harmony & 58.877 & 88.11 & 0.9741 \\
$\quad$ Search Optimization (CTLHSO) Algorithm [33] & & & \\
ILSA (Proposed method) & 55.92 & 88.71 & 1.0223 \\
\hline
\end{tabular}

Fig. 12 Power loss for comparative analysis of proposed method with existing methods

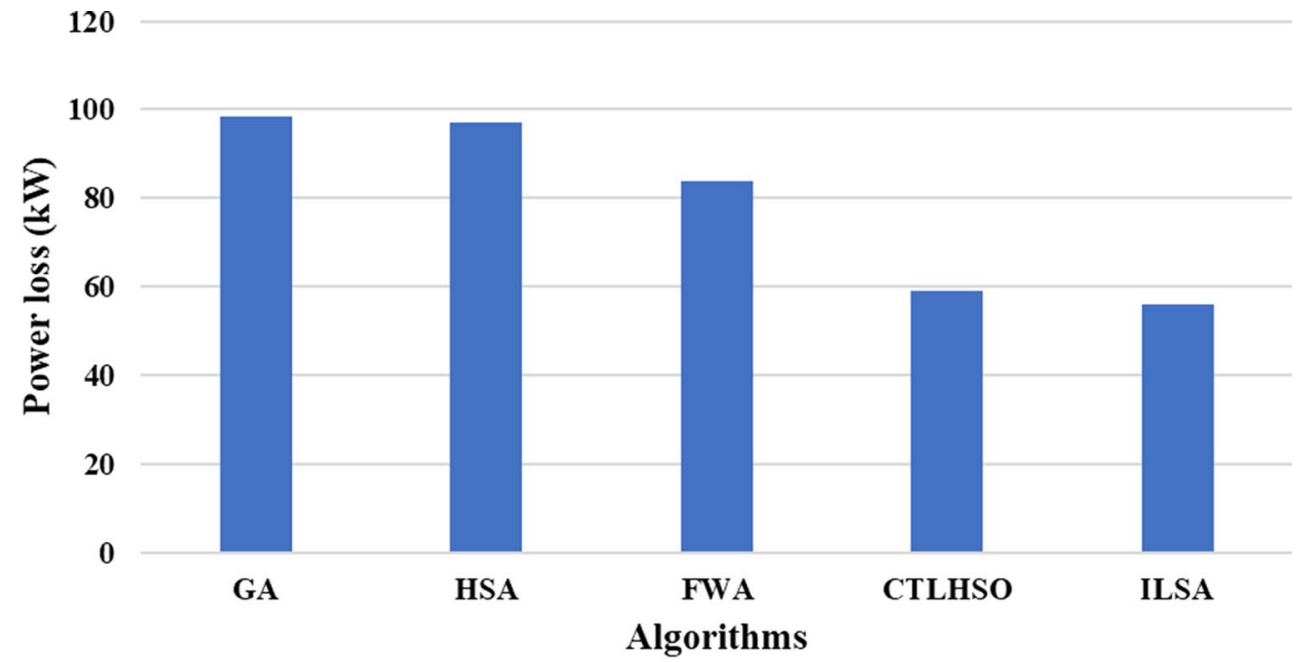

n Power loss

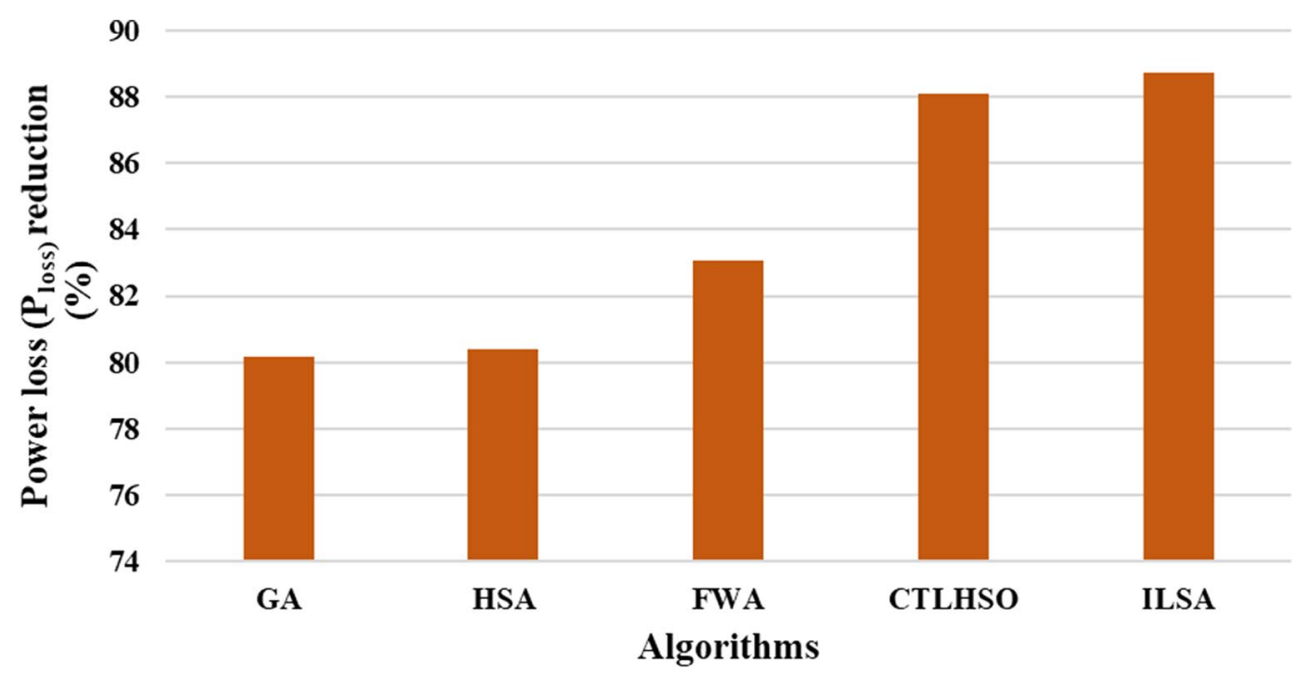

- Power loss reduction (\%)

Fig. $13 \% \mathrm{P}_{\text {loss }}$ reduction for comparative analysis of proposed method with existing methods 
Fig. $14 \mathrm{~V}_{\min }$ for comparative analysis of proposed method with existing methods

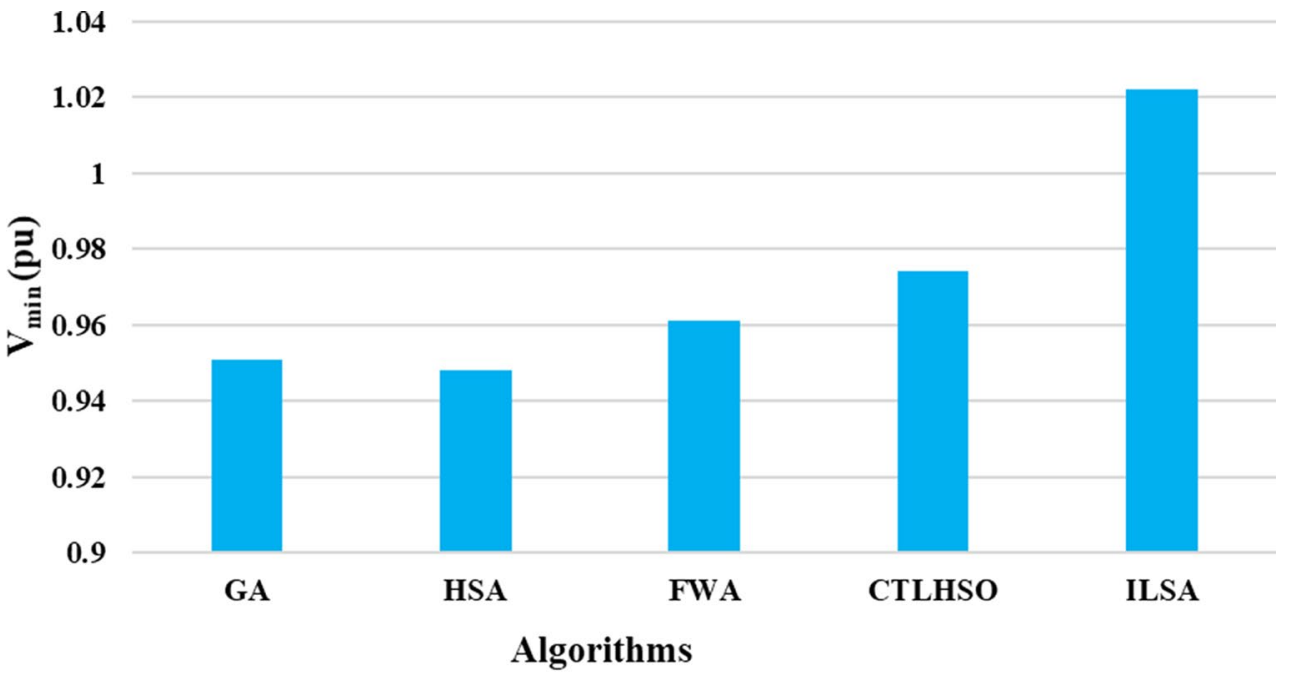

Minimum voltage (pu)
Acknowledgements The authors wish to express their sincere thanks to the Management of Ponjesly College of Engineering, Nagercoil, Tamilnadu, India for their support in carrying out this research work. The authors also thank the reviewers for their valuable suggestions in improving the quality of the research article.

Author Contributions Methodology, IG; software, IG; validation, IG, JP; formal analysis, IG; investigation, IG; resources, IG; writingoriginal draft preparation, IG, JP; writing — review and editing, IG, JP; visualization, IG, JP; supervision, JP.

Funding This research has no significant financial support that could have influenced its outcome.

\section{Declarations}

Conflict of interest The authors declare no conflicts of interest.

Open Access This article is licensed under a Creative Commons Attribution 4.0 International License, which permits use, sharing, adaptation, distribution and reproduction in any medium or format, as long as you give appropriate credit to the original author(s) and the source, provide a link to the Creative Commons licence, and indicate if changes were made. The images or other third party material in this article are included in the article's Creative Commons licence, unless indicated otherwise in a credit line to the material. If material is not included in the article's Creative Commons licence and your intended use is not permitted by statutory regulation or exceeds the permitted use, you will need to obtain permission directly from the copyright holder. To view a copy of this licence, visit http://creativecommons.org/licenses/by/4.0/.

\section{References}

1. Xu, Y., Dong, Z.Y., Zhang, R., et al.: Multi-Timescale coordinated voltage/var control of high renewable-penetrated distribution networks. IEEE Trans. Power Syst. 99, 1-1 (2017)
2. Singh, D., Misra, R.K.: Effect of load models in distributed generation planning. IEEE Trans. Power Syst. 22(4), 2204-2212 (2007)

3. Bokhari, A., Raza, A., Diaz-Aguilo, M., et al.: Combined effect of CVR and DG penetration in the voltage profile of low-voltage secondary distribution networks. IEEE Trans. Power Deliv. 31(1), 286-293 (2016)

4. Padilha-Feltrin, A., Rodezno, D.A.Q., Mantovani, J.R.S.: VoltVAR multi-objective optimization to peak-load relief and energy efficiency in distribution networks. IEEE Trans. Power Deliv. 30(2), 618-626 (2015)

5. Zhaoyu, W., Bokan, C., Jianhui, W., et al.: Stochastic DG placement for conservation voltage reduction based on multiple replications procedure. IEEE Trans. Power Deliv. 30(3), 1039-1047 (2015)

6. Wang, Z., Wang, J.: Time-varying stochastic assessment of conservation voltage reduction based on load modelling. IEEE Trans. Power Syst. 29(5), 2321-2328 (2014)

7. Hedayati, H., Nabaviniaki, S.A., Akbarimajd, A.: A method for placement of DG units in distribution networks. IEEE Trans. Power Deliv. 23, 1620-1628 (2008)

8. Al Abri, R.S., El-Saadany, E.F., Atwa, Y.M.: Optimal placement and sizing method to improve the voltage stability margin in a distribution system using distributed generation. IEEE Trans. Power Syst. 28(1), 326-334 (2013)

9. Kroposki, B., Sen, P.K., Malmedal, K.: Optimum sizing and placement of distributed and renewable energy sources in electric power distribution systems. IEEE Trans. Ind. Appl. 49(6), 2741-2752 (2013)

10. Hung, D.Q., Mithulananthan, N.: Multiple distributed generator placement in primary distribution networks for loss reduction. IEEE Trans. Ind. Electron. 60(4), 1700-1708 (2013)

11. Mosbah, Mustafa, Arif, Salem, Zine, Rabie, Mohammed, Ridha D., Oudjana, Samir H.: Optimal Size and location of PV based DG-unit in transmission system using GA method for loss reduction. J Electr Eng 17, 4 (2017)

12. Ghahremani, E., Kamwa, I.: Optimal placement of multiple-type FACTs devices to maximize power system loadability using a generic graphical user interface. IEEE Trans. Power Syst. 28(2), 764-778 (2013)

13. Zhu, J., Cheung, K., Hwang, D., et al.: Operation Strategy for improving voltage profile and reducing system loss. IEEE Trans. Power Deliv. 25(1), 390-397 (2010) 
14. Saravanan, M., Slochanal, S.M.R., Venkatesh, P., Abraham, P.S.: Application of PSO technique for optimal location of FACTS devices considering cost of installation and system loadability. ELSEVIER Electr. Power Syst. Res. 77, 276-283 (2007)

15. Pathan, S.R., Panwar, D.: A smart channel estimation approach for LTE systems using PSO algorithm. Ann. Optim. Theory Pract. 3, 3 (2020)

16. Merini, K., Rami, A.: Optimal allocation and voltage Stability in electrical network by using STATCOM. J. Electr. Eng. 16, 1-9 (2016)

17. Abd-Elazim, S.M., Ali, E.S.: Optimal allocation of STATCOM in multi-machine power system for increasing loadability by Cuckoo Search algorithm. ELSEVIER Int J Electr. Power Energy Syst. 80, 240-251 (2016)

18. Tripathy, M., Mishra, S.: Bacteria Foraging based solution to optimize both real power loss and voltage stability limit. IEEE Trans. Power Syst. 22(1), 240-248 (2007)

19. Karthikaikannan, D., Ravi, G.: Optimal location and setting of FACTS devices for reactive power compensation using harmony search algorithm. Automatika 57(4), 881-892 (2016)

20. Sri Kumar, K., Ranadev, K.: Optimal allocation and sizing of Multiple Distributed generation units using improved HSA. J. Electr. Eng. 18, 6 (2018)

21. Mauryan, C., Sivalingam, K., Ramachandran, S., Sakthi, P.S., Rajamani: Reactive power optimization in a power system network through metaheuristic algorithm. Turk. J. Elec. Eng. Comp. Sci. 25, 4615-4623 (2017)

22. Esmaili, M., Ghamsari-Yazdel, M., NimaAmjady, C.Y., Chung: Optimal placement of resistive/inductive SFCLs considering short-circuit levels using complex artificial bee colony algorithm. IET Gener. Transm. Distrib. 13(24), 5561-5568 (2019)

23. Mahadevan, K., Kannan, P.S.: Comprehensive learning particle swarm optimization for reactive power dispatch. ELSEVIER App. Soft. Computing 10, 641-652 (2010)

24. Jafari, A., Ganjehlou, H.G., Khalili, T., Mohammadi-Ivatloo, B., Bidram, A., Siano, P.: A two-loop hybrid method for optimal capacitors in distribution networks. IEEE Power Energy Soc. Sect. 8, 38892-38906 (2020)
25. Ansari, Muhammad Mohsin, Guo, Chuangxin, Shaikh, Muhammad Suhail, Chopra, Nitish, Haq, Inzamamul, Shen, Lingbing: Planning for distribution system with grey wolf optimization method. J. Electr. Eng. Technol. 15, 1485 (2020)

26. Rahimian, M.: Measuring efficiency in DEA by differential evolution algorithm. Ann. Optim. Theory Pract. 2(1), 19-26 (2019)

27. Garg, Harish: A Hybrid GA-GSA Algorithm for Optimizing the Performance of an Industrial System by Utilizing Uncertain Data. In: Vasant, P. (ed.) Handbook of Research on Artificial Intelligence Techniques and Algorithms, pp. 1-35. IGI Global (2015)

28. Garg, H.: A hybrid PSO-GA algorithm for constrained optimization problems. Appl. Math. Comput. 274, 292-305 (2016)

29. Patwal, Rituraj Singh, Narang, Nitin, Garg, Harish: A novel TVAC-PSO based mutation strategies algorithm for generation scheduling of pumped storage hydrothermal system incorporating solar units. Energy 142, 822 (2017)

30. Garg, Harish: A hybrid GSA-GA algorithm for constrained optimization problems. Inf. Sci. 478, 499 (2018)

31. Srinivasa Rao, R., Ravindra, K., Satisk, K., Narasimham, S.V.L.: Power loss minimization in distribution system using network reconfiguration in the presence of distributed generation. IEEE Trans. Power Syst. 28(1), 317-325 (2013)

32. Imran, A.M., Kowsalya, M., Kothari, D.P.: A novel integration technique for optimal network reconfiguration and distributed generation placement in power distribution networks. Int J Electr Power Energy Syst. 63, 461-472 (2014)

33. Quadri, Imran Ahmad, Bhowmick, A.: Hybrid technique for simultaneous network reconfiguration and optimal placement of distributed generation resources. Soft Comput. 24, 1-22 (2019)

Publisher's Note Springer Nature remains neutral with regard to jurisdictional claims in published maps and institutional affiliations. 